Published in final edited form as:

Ann Surg Oncol. 2014 October ; 21(11): 3473-3480. doi:10.1245/s10434-014-3748-9.

\title{
Role of Pre-operative Magnetic Resonance Imaging in the Surgical Management of Early Stage Breast Cancer
}

\author{
Sheenu Chandwani, PhD ${ }^{1,2,3}$, Prethibha A. George, PhD ${ }^{1}$, Michelle Azu, MD ${ }^{1,4}$, Elisa V. \\ Bandera, MD, PhD ${ }^{1,2}$, Christine B. Ambrosone, $\mathrm{PhD}^{5}$, George G. Rhoads, MD, $\mathbf{M P H}^{1,2}$, and \\ Kitaw Demissie, MD, PhD ${ }^{1,2,3}$ \\ ${ }^{1}$ Department of Epidemiology, Rutgers School of Public Health, Piscataway, NJ \\ ${ }^{2}$ Rutgers Cancer Institute of New Jersey, New Brunswick, NJ \\ ${ }^{3}$ Institute for the Elimination of Health Disparities, Newark, NJ \\ ${ }^{4}$ Chilton Hospital, Pompton Plains, NJ \\ ${ }^{5}$ Department of Cancer Prevention and Control, Roswell Park Cancer Institute, Buffalo, NY
}

\section{Abstract}

Purpose-To examine the role of pre-operative magnetic resonance imaging (pMRI) on time to surgery and rates of re-operation and contralateral prophylactic mastectomy (CPM) using a population-based study of New Jersey breast cancer (BC) patients.

Methods-The study included 289 African-American and 320 white women who participated in the Breast Cancer Treatment Disparity Study and underwent breast surgery for newly diagnosed early stage BC between 2005 and 2010. Patients were identified through rapid case ascertainment by the New Jersey State Cancer Registry. Association between pMRI and time to surgery was examined using linear regression, and with re-operation and CPM using binomial regression.

Results-Half (49.9\%) of the study population received pMRI, with higher use for whites compared to African-Americans (62.5\% versus 37.5\%). After adjusting for potential confounders, patients with pMRI than those without, experienced significantly longer time to initial surgery (geometric mean $=38.7$ days; $95 \%$ confidence interval: $34.8,43.0$ versus 26.5 days; $95 \%$ confidence interval: $24.3,29.0$ ), significantly higher rate of CPM (relative risk $[R R]=1.82 ; 95 \%$ confidence interval: $1.06,3.12)$, and non-significant lower rate of re-operation $(\mathrm{RR}=0.76 ; 95 \%$ confidence interval [CI]: 0.54, 1.08).

Conclusions-pMRI was associated with significantly increased time to surgery and higher rate of CPM, but it did not affect the rate of re-operation. Physicians and patients should consider these findings when making surgical decisions based on pMRI findings.

Corresponding Author: Sheenu Chandwani, PhD, Rutgers School of Public Health, Department of Epidemiology, 683 Hoes Lane West, Piscataway, NJ 08854, Phone: 732-235-4352; Fax: 732-235-5418, sheenu.chandwani@ rutgers.edu.

Disclosures: No potential conflicts of interest. 


\section{INTRODUCTION}

Current guidelines recommend bilateral mammography as the primary modality and if necessary, ultrasonography to determine tumor extent pre-operatively and plan surgical treatment of early stage breast cancer (BC). ${ }^{1}$ There are no recommendations supporting the routine use of pre-operative magnetic resonance imaging (pMRI) in surgical planning of BC due to lack of data showing survival advantage associated with its use. In addition, the few studies that examined the impact of pMRI on BC recurrence have failed to show any benefits. ${ }^{2-4}$ Despite the lack of proven benefits on patient outcomes, use of pMRI has increased significantly in the past decade. ${ }^{5-8}$

The growing popularity of pMRI has been based on the assumption that its increased detection capability will result in wider excision and removal of additional disease and therefore, will improve immediate surgical outcomes. ${ }^{9}$ Research evaluating pMRI mostly includes single institution studies on re-operation where majority have found no improvement related to pMRI. ${ }^{3,4,10-16}$ There are also concerns that pMRI may be associated with recent increases in contralateral prophylactic mastectomy (CPM), and procedures required to evaluate the findings of pMRI may result in unnecessary increases in time to surgery. 5,7,8,17,18 The limited number of studies that have examined the role of pMRI on CPM rates and time to surgery either reported conflicting findings or were unable to adjust for important confounders. ${ }^{7,8,18-21}$ The available evidence is therefore insufficient to determine whether pMRI should be included in the routine work-up of BC patients. We conducted a population-based study to investigate the role of pMRI on time to surgery as well rates of re-operation and CPM among early stage BC patients.

\section{METHODS}

\section{Study Population and Data Collection}

The study population was selected from patients included in the Breast Cancer Treatment Disparity Study (BCTDS). The BCTDS is composed of African-American (AA) and white women who participated in the Women's Circle of Health Study (WCHS), diagnosed with stage I, II, and $\mathrm{T}_{3} \mathrm{~N}_{1} \mathrm{M}_{0} \mathrm{BC}$ between 2005-2010, with no prior history of cancer other than non-melanoma skin cancer, and age $\leq 85$ years. The WCHS is a multi-site case-control study in New York City and New Jersey (NJ) designed to evaluate risk factors for early and aggressive BC in AA and white women. ${ }^{22,23}$ The BCTDS cohort included NJ cases from the WCHS who were identified from all major hospitals in seven counties, including Bergen, Essex, Hudson, Mercer, Middlesex, Passaic, and Union through rapid case ascertainment by the NJ State Cancer Registry staff. A total of 634 patients comprised the BCTDS population. Written informed consents were obtained from all patients who agreed to participate and the study was approved by institutional review board at all participating institutions.

All BCTDS patients were included in the current study, except for those who did not undergo breast excision following diagnosis $(n=25)$ resulting in a total of 609 patients. Patients included in the study consented to release of their medical records and provided contact information of health care providers involved in their BC care. These providers were contacted to obtain medical records for abstracting information on socio-demographics, 
family history, cancer suspicion, pre-operative and diagnostic investigations, tumor pathology results, and surgical and adjuvant treatment(s). Data was also collected on date of cancer suspicion as well as dates of administration for various tests, procedures, and adjuvant treatments. Abstractors were blinded to study hypothesis and they participated in a standardized training to ensure uniformity of information ascertainment, check for completeness, and prevent systematic differences in data collection between abstractors.

\section{Pre-operative MRI}

In all cases, breast cancer was pathologically confirmed either by percutaneous or surgical biopsy. Consequently, first breast excision performed after pathologic diagnosis was defined as initial surgery and consisted of either breast conserving surgery (BCS) or mastectomy. A patient who received MRI any time between the date of cancer suspicion and the date of initial surgery was classified as pMRI recipient. Patients who did not receive MRI in this time period were categorized into the no pMRI group.

\section{Outcomes}

Time to surgery was calculated as interval in days from pathologic diagnosis to initial surgery. Subjects who received neo-adjuvant chemotherapy were further excluded from analysis of time to surgery $(n=33)$. Re-operation was defined as at least one repeat operation performed after initial surgery. It consisted of either re-excision following initial BCS or initial mastectomy, or mastectomy following initial BCS. CPM was defined as removal of the unaffected breast along with affected breast.

\section{Additional Variables}

We examined socio-demographics and clinical characteristics including, age at diagnosis, race, education, health insurance, body mass index (BMI), family history of BC (first degree, second degree, or none), method of cancer detection (by patient, physician, or screening mammography), receipt of additional investigations (diagnostic mammogram and ultrasound, additional biopsy following diagnosis, and genotype testing done for mutations in BRCA1 and BRCA2 genes), and method of diagnosis (percutaneous or surgical biopsy). Tumor characteristics examined were: grade, histology, size, lymph node status, presence of multifocality or multicentricity, and estrogen, progesterone, and human epidermal growth factor 2 receptor statuses. Margin status at initial surgery was classified into positive, close ( $\leq 1 \mathrm{~mm}$ ), and negative. Treatment information including type of initial surgery, surgical facility (teaching or community), and receipt of adjuvant chemotherapy and hormonal therapy was also obtained.

\section{Statistical Analysis}

Socio-demographic, clinical characteristics, tumor pathology, and treatment(s) status of the study population were tabulated by receipt of pMRI. Time to surgery, and rates of reoperation and CPM were compared between the two pMRI groups as well by various subject characteristics. Time to surgery (days) was log transformed due to its positively skewed distribution and regression diagnostics were utilized to check for influential observations. Four outliers were identified that were further excluded from analysis of time 
to surgery (final $n=572$ ). Linear regression through general linear model was used to estimate unadjusted and adjusted geometric mean with 95\% confidence interval (CI) for time to surgery. Geometric means were obtained by exponentiation of parameter estimates from linear regression. Re-operation and CPM rates were examined for all 609 patients in the study. They were reported as percentages, and chi-square test was used to compare rates. Univariate and multivariate binomial regression models were utilized to examine the association between pMRI, and re-operation and CPM. The binomial associations were expressed as relative risk (RR) and 95\% CI using nonlinear programming. The variables included in the multivariate models were selected based on prior knowledge as well the association of the variable with both pMRI and study outcomes while keeping a parsimonious approach in mind. The adjusted model for time to surgery included age, race, education, insurance, and type of initial surgery. The multivariate model for re-operation was adjusted for age, race, education, insurance, BMI, method of diagnosis, histology, multifocality or multicentricity, and surgical facility. The multivariate model for CPM was adjusted for age, race, education, insurance, BMI, family history, genotype testing, clinical presentation, multifocality or multicentricity, and surgical facility. Associations with pvalues less than 0.05 were considered statistically significant. We also explored findings from additional biopsy that patients received after their pathologic diagnosis by receipt of pMRI. All analyses were conducted using SAS version 9.3 (SAS Institute Inc., Cary, NC).

\section{RESULTS}

Of the total 609 BC patients included in the study, 49.9\% (304/609) received pMRI. As shown in Table 1, patients receiving pMRI compared to those without, were more likely to be younger, of white race, with higher education, covered by private health insurance, and of normal weight. They were also more likely to have family history of BC, self-discover their $\mathrm{BC}$, undergo diagnostic ultrasound and genotype testing, receive additional biopsies, and get diagnosed by percutaneous biopsy. While examining tumor and treatment characteristics (Table 2), patients who received pMRI more commonly had positive lymph nodes and multifocal or multicentric cancer. However, no differences were seen in tumor grade, histology, and size, surgical margins, receptor status, receipt of adjuvant treatment, and surgical facility.

Study outcomes by receipt of pMRI are shown in Table 3. Geometric mean days to initial surgery was 35.0 (95\% CI: 32.6, 37.7) for patients with pMRI and 25.9 (95\% CI: 24.1, 27.8) for patients without pMRI $(p<0.001)$. Overall, rate of re-operation was $19.2 \%(117 / 609)$ and rate of CPM was $10.7 \%$ (65/609). No difference in rate of re-operation was observed between patients with and without pMRI ( $18.1 \%$ and $20.3 \%$, respectively; $p=0.484)$. A significantly higher rate of CPM was observed for patients with pMRI than for those without (16.1\% and $5.2 \%$, respectively; $p<0.001)$.

Distribution of study outcomes by different patient characteristics are presented in Table 4 . Time to initial surgery was significantly longer for AAs and for mastectomy patients. Higher re-operation rates were seen for higher BMI, diagnosis by percutaneous biopsy, positive or close margins on initial surgery, and receipt of surgery in community hospital. On the other hand, rates of CPM were higher among those with younger age, white race, private health 
insurance, lower BMI, family history of BC, self-recognized cancer, receipt of genotype test, and presence of multifocal or multicentric tumor.

Table 5 presents unadjusted and adjusted association between pMRI and study outcomes. Results from adjusted linear regression showed that patients who received pMRI experienced significantly longer time from diagnosis to initial surgery (geometric mean= 38.7 days; 95\% CI: 34.8, 43.0) as compared to patients who did not (geometric mean $=26.5$ days; 95\% CI: 24.3, 29.0). Receipt of pMRI was not associated with significant reduction in re-operation rate, both in the unadjusted $(\mathrm{RR}=0.89 ; 95 \% \mathrm{CI}: 0.64,1.23)$ and adjusted $(\mathrm{RR}=$ 0.76; 95\% CI: $0.54,1.08)$ models. In the unadjusted model, risk of undergoing CPM was more than three times higher for patients who received pMRI compared to those without $(\mathrm{RR}=3.07 ; 95 \% \mathrm{CI}: 1.79,5.28)$. After adjusting for potential confounders including age, race, education, insurance, BMI, family history, genotype testing, clinical presentation, multifocality or multicentricity, and surgical facility, receipt of pMRI was associated with $\mathrm{RR}=1.82(95 \% \mathrm{CI}: 1.06,3.12)$ of undergoing CPM.

The exploratory analysis showed that $10.2 \%$ (31/304) and 4.6\% (14/305) patients with and without pMRI respectively, received additional biopsy following the pathological diagnosis. These additional biopsies resulted in positive findings (including additional foci of invasive or in-situ carcinoma) among 16/31 (51.6\%) patients with pMRI and 8/14 (57.1\%) patients without pMRI, $p>0.05$.

\section{DISCUSSION}

Use of pMRI has gained worldwide popularity in surgical planning of BC due to its proven superior accuracy in detecting additional disease compared to conventional imaging. Due to steep rise in pMRI use in the absence of improved patient outcomes, it becomes clinically meaningful to understand its impact on short-term surgical outcomes. In this study we examined the association of pMRI with time to surgery, re-operation, and CPM among early stage BC patients. Approximately half of the study population received pMRI, and $18.8 \%$ and $10.7 \%$ underwent re-operation and CPM, respectively. Patients receiving pMRI experienced significantly longer time to initial surgery and 1.82 times risk of undergoing $\mathrm{CPM}$; but no difference in re-operation rate as compared to those who did not receive pMRI.

Only two US based studies to date have examined the impact of pMRI on time to surgical treatment. Bleicher et al reported mean times of 57 and 38 days $(\mathrm{p}=0.01)$, and Hulvat et al reported median times of 43 and 32 days $(\mathrm{p}=0.054)$ in $\mathrm{pMRI}$ and no pMRI groups, respectively. ${ }^{18,21}$ But these studies reported unadjusted results which can lead to biased estimates due to a large impact of patient characteristics like socioeconomic status, access to care, and race as well as tumor characteristics on treatment delay. This was true for our study population as well, as longer time to surgery was observed for AAs and for those undergoing mastectomy. After adjusting for differences related to age, race, education, insurance, and type of initial surgery, we found that pMRI subjects experienced a significantly longer time to initial surgery (38.9 days versus 27.5 days). The longer delay seen for pMRI group can be explained by additional tests and biopsies that are conducted to investigate MRI findings. The difference seen between the two groups may not have a 
detrimental effect on treatment outcome, but longer time taken to initiate surgery may result in increased patient anxiety and treatment dissatisfaction. ${ }^{21}$

In large part, single institution studies have examined differences in re-excision rates by receipt of pMRI. The majority of these reports showed no differences $3,10,11,13,15,16$, except for one by Mann et al where a significantly lower rate of re-excision at 5\% was seen for patients who received pMRI in comparison to $15 \%$ for those who did not. ${ }^{12}$ Two recent European randomized trials evaluated the efficacy of pMRI among BC patients. One of them reported no association between pMRI and re-excisions within 6 months of randomization (odds ratio $=0.96 ; 95 \% \mathrm{CI}$ : 0.75 to 1.24$).{ }^{4}$ The second trial on the other hand, found significant increase in re-excisions after BCS in the pMRI group (34\%) versus the control group (12\%). ${ }^{14}$ Rate of re-operation seen in our study is similar to these pre-existing reports and concurs with most of the available evidence that there is no benefit associated with pMRI on re-operation.

There has been a significant increasing trend in CPM rates nationwide 24,25 even though it provides minimal or no survival benefits. ${ }^{26,27} \mathrm{CPM}$ is particularly recommended for patients who are at high risk of developing bilateral $\mathrm{BC} ;{ }^{28-32}$ however, majority of women who choose to undergo CPM are not at high risk. ${ }^{7,19,33,34}$ A combination of both patient and clinical factors has been associated with its increased use. Few studies have examined pMRI as a predictor of CPM and reported different conclusions. ${ }^{7,8,19,20}$ Sorbero et al and King et al showed significantly increased risk of CPM associated with pMRI; ${ }^{7,8}$ whereas, two studies did not find any association. ${ }^{19,20}$ Additionally, many of them were limited in their ability to control for important confounders. For example almost all of them did not have information on socio-economic variables like education and insurance and some were unable to adjust important clinical variables as well. Results from our analysis also show that pMRI was associated with high risk of CPM, although, the RR declined considerably after adjusting for several relevant socio-demographic and clinical predictors (unadjusted $\mathrm{RR}=3.07$ versus adjusted $\mathrm{RR}=1.82$ ). In our study, patients receiving $\mathrm{CPM}$ compared to those who did not, were selectively very different. CPM patients were more likely to be younger, whites, of higher socioeconomic status, privately insured, with family history of $\mathrm{BC}$ and therefore, comprised a group of more health conscious patients. It is possible that these patients may proactively ask for pMRI and/or the treating oncologist may prefer to do more extensive work-ups on these patients. As a result, after adjusting for these factors the RR was minimized, but it was not eliminated completely; hence suggesting that pMRI is one of the independent predictors that may influence patients' decision to opt for CPM.

A longer delay or excess of surgeries observed for pMRI group can be considered useful if, in fact, it increases the chances of identifying additional cancer as compared to no pMRI group. In our study, although the pMRI group was twice more likely to receive additional biopsy, no difference was seen in proportions with positive findings on biopsies by receipt of pMRI.

Our study had some potential limitations. We were unable to evaluate that whether the decision to undergo CPM was based on findings of pMRI or not. We also did not have data on other additional tests that may have been performed to investigate pMRI findings and 
their influence on surgical outcomes. The study however, utilizes the strength of detailed clinical information available in medical records such that confounding by indication is not a major issue. Additionally, this is a population-based study including many hospitals in a diverse area which provides increased generalizability about impact of pMRI on surgical outcomes in contrast to most of the existing reports that are single institution based.

In conclusion, we found that pMRI did not offer any substantial benefits in surgical management of BC patients. The re-operation rates did not differ significantly by receipt of pMRI. Additionally, pMRI had a significant influence on receipt of CPM and in increasing time to surgery. We recommend that patients should be counseled about the lack of benefits of pMRI during surgical decision making.

\section{Acknowledgments}

This work was supported by grants from the American Cancer Society (RSGT-07-291-01-CPHPS), the Susan G. Komen Breast Cancer Foundation (POP131006), the National Cancer Institute (R01CA133264, R01 CA100598, P01 CA151135, K22 CA138563, P30CA072720, P30 CA016056), US Army Medical Research and Material Command (DAMD-17-01-1-0334), the Breast Cancer Research Foundation and a gift from the Philip L Hubbell family and the Buckingham Foundation. The funding agencies played no role in study design; collection, analysis, and interpretation of data; and writing of the manuscript and decision to submit the manuscript for publication. The study team is grateful for medical, surgical and radiation oncologists and primary care physicians who understood the value of research and helped us obtain the medical records of patients without which the conduct of the study would have been impossible.

\section{References}

1. NCCN. Clinical Practice Guidelines in Oncology: Breast Cancer, Version 3.2013. National Comprehensive Cancer Network Inc; 2013.

2. Solin LJ, Orel SG, Hwang WT, Harris EE, Schnall MD. Relationship of breast magnetic resonance imaging to outcome after breast-conservation treatment with radiation for women with early-stage invasive breast carcinoma or ductal carcinoma in situ. J Clin Oncol. Jan 20; 2008 26(3):386-391. [PubMed: 18202414]

3. Hwang N, Schiller DE, Crystal P, Maki E, McCready DR. Magnetic resonance imaging in the planning of initial lumpectomy for invasive breast carcinoma: its effect on ipsilateral breast tumor recurrence after breast-conservation therapy. Ann Surg Oncol. Nov; 2009 16(11):3000-3009. [PubMed: 19603233]

4. Turnbull L, Brown S, Harvey I, et al. Comparative effectiveness of MRI in breast cancer (COMICE) trial: a randomised controlled trial. Lancet. Feb 13; 2010 375(9714):563-571. [PubMed: 20159292]

5. Katipamula R, Degnim AC, Hoskin T, et al. Trends in mastectomy rates at the Mayo Clinic Rochester: effect of surgical year and preoperative magnetic resonance imaging. J Clin Oncol. Sep 1; 2009 27(25):4082-4088. [PubMed: 19636020]

6. Sommer CA, Stitzenberg KB, Tolleson-Rinehart S, Carpenter WR, Carey TS. Breast MRI utilization in older patients with newly diagnosed breast cancer. J Surg Res. Sep; 2011 170(1):7783. [PubMed: 21658724]

7. King TA, Sakr R, Patil S, et al. Clinical management factors contribute to the decision for contralateral prophylactic mastectomy. J Clin Oncol. Jun 1; 2011 29(16):2158-2164. [PubMed: 21464413]

8. Sorbero ME, Dick AW, Beckjord EB, Ahrendt G. Diagnostic breast magnetic resonance imaging and contralateral prophylactic mastectomy. Ann Surg Oncol. Jun; 2009 16(6):1597-1605. [PubMed: 19330381]

9. Teller P, Jefford VJ, Gabram SG, Newell M, Carlson GW. The utility of breast MRI in the management of breast cancer. Breast J. Jul-Aug;2010 16(4):394-403. [PubMed: 20545940] 
10. Pengel KE, Loo CE, Teertstra HJ, et al. The impact of preoperative MRI on breast-conserving surgery of invasive cancer: a comparative cohort study. Breast Cancer Res Treat. Jul; 2009 116(1): 161-169. [PubMed: 18807269]

11. McGhan LJ, Wasif N, Gray RJ, et al. Use of preoperative magnetic resonance imaging for invasive lobular cancer: good, better, but maybe not the best? Ann Surg Oncol. Oct; 2010 17( Suppl 3): 255-262. [PubMed: 20853043]

12. Mann RM, Loo CE, Wobbes T, et al. The impact of preoperative breast MRI on the re-excision rate in invasive lobular carcinoma of the breast. Breast Cancer Res Treat. Jan; 2010 119(2):415422. [PubMed: 19885731]

13. Miller BT, Abbott AM, Tuttle TM. The influence of preoperative MRI on breast cancer treatment. Ann Surg Oncol. Feb; 2012 19(2):536-540. [PubMed: 21751044]

14. Peters NH, van Esser S, van den Bosch MA, et al. Preoperative MRI and surgical management in patients with nonpalpable breast cancer: the MONET - randomised controlled trial. Eur J Cancer. Apr; 2011 47(6):879-886. [PubMed: 21195605]

15. Weber JJ, Bellin LS, Milbourn DE, Verbanac KM, Wong JH. Selective preoperative magnetic resonance imaging in women with breast cancer: no reduction in the reoperation rate. Arch Surg. Sep; 2012 147(9):834-839. [PubMed: 22987175]

16. Grady I, Gorsuch-Rafferty H, Hadley P. Preoperative staging with magnetic resonance imaging, with confirmatory biopsy, improves surgical outcomes in women with breast cancer without increasing rates of mastectomy. Breast J. May-Jun;2012 18(3):214-218. [PubMed: 22487017]

17. Houssami N, Hayes DF. Review of preoperative magnetic resonance imaging (MRI) in breast cancer: should MRI be performed on all women with newly diagnosed, early stage breast cancer? CA: a cancer journal for clinicians. Sep-Oct;2009 59(5):290-302. [PubMed: 19679690]

18. Bleicher RJ, Ciocca RM, Egleston BL, et al. Association of routine pretreatment magnetic resonance imaging with time to surgery, mastectomy rate, and margin status. Journal of the American College of Surgeons. Aug; 2009 209(2):180-187. quiz 294-185. [PubMed: 19632594]

19. Arrington AK, Jarosek SL, Virnig BA, Habermann EB, Tuttle TM. Patient and surgeon characteristics associated with increased use of contralateral prophylactic mastectomy in patients with breast cancer. Ann Surg Oncol. Oct; 2009 16(10):2697-2704. [PubMed: 19653045]

20. Yi M, Hunt KK, Arun BK, et al. Factors affecting the decision of breast cancer patients to undergo contralateral prophylactic mastectomy. Cancer Prev Res (Phila). Aug; 2010 3(8):1026-1034. [PubMed: 20647335]

21. Hulvat M, Sandalow N, Rademaker A, Helenowski I, Hansen NM. Time from diagnosis to definitive operative treatment of operable breast cancer in the era of multimodal imaging. Surgery. Oct; 2010 148(4):746-750. discussion 750-741. [PubMed: 20708761]

22. Ambrosone CB, Ciupak GL, Bandera EV, et al. Conducting Molecular Epidemiological Research in the Age of HIPAA: A Multi-Institutional Case-Control Study of Breast Cancer in AfricanAmerican and European-American Women. J Oncol. 2009; 2009:871250. [PubMed: 19865486]

23. Bandera EV, Chandran U, Zirpoli G, et al. Body size in early life and breast cancer risk in African American and European American women. Cancer Causes Control. Dec; 2013 24(12):2231-2243. [PubMed: 24113797]

24. Tuttle TM, Habermann EB, Grund EH, Morris TJ, Virnig BA. Increasing use of contralateral prophylactic mastectomy for breast cancer patients: a trend toward more aggressive surgical treatment. J Clin Oncol. Nov 20; 2007 25(33):5203-5209. [PubMed: 17954711]

25. Yao K, Stewart AK, Winchester DJ, Winchester DP. Trends in contralateral prophylactic mastectomy for unilateral cancer: a report from the National Cancer Data Base, 1998-2007. Ann Surg Oncol. Oct; 2010 17(10):2554-2562. [PubMed: 20461470]

26. Yao K, Winchester DJ, Czechura T, Huo D. Contralateral prophylactic mastectomy and survival: report from the National Cancer Data Base, 1998-2002. Breast Cancer Res Treat. Dec; 2013 142(3):465-476. [PubMed: 24218052]

27. Bedrosian I, Hu CY, Chang GJ. Population-based study of contralateral prophylactic mastectomy and survival outcomes of breast cancer patients. J Natl Cancer Inst. Mar 17; 2010 102(6):401-409. [PubMed: 20185801] 
28. Storm HH, Jensen OM. Risk of contralateral breast cancer in Denmark 1943-80. Br J Cancer. Sep; 1986 54(3):483-492. [PubMed: 3756084]

29. Prior P, Waterhouse JA. The incidence of bilateral breast cancer: II. A proposed model for the analysis of coincidental tumours. Br J Cancer. May; 1981 43(5):615-622. [PubMed: 7248146]

30. Adami HO, Bergstrom R, Hansen J. Age at first primary as a determinant of the incidence of bilateral breast cancer. Cumulative and relative risks in a population-based case-control study. Cancer. Feb 1; 1985 55(3):643-647. [PubMed: 3965112]

31. Michowitz M, Noy S, Lazebnik N, Aladjem D. Bilateral breast cancer. J Surg Oncol. Oct; 1985 30(2):109-112. [PubMed: 4079423]

32. Robbins GF, Berg JW. Bilateral Primary Breast Cancer; a Prospective Clinicopathological Study. Cancer. Dec.1964 17:1501-1527. [PubMed: 14239677]

33. Dupont EL, Kuhn MA, McCann C, Salud C, Spanton JL, Cox CE. The role of sentinel lymph node biopsy in women undergoing prophylactic mastectomy. Am J Surg. Oct; 2000 180(4):274-277. [PubMed: 11113434]

34. Yi M, Meric-Bernstam F, Middleton LP, et al. Predictors of contralateral breast cancer in patients with unilateral breast cancer undergoing contralateral prophylactic mastectomy. Cancer. Mar 1; 2009 115(5):962-971. [PubMed: 19172584] 


\section{Synopsis}

This study examined the impact of pre-operative MRI on surgical management of early stage breast cancer patients. While pre-operative MRI did not impact re-operation rates, it significantly increased time to surgery and rate of contralateral prophylactic mastectomy. 
Table 1

Socio-demographic and clinical characteristics of the study population, by receipt of pMRI

\begin{tabular}{|c|c|c|c|}
\hline Characteristics, n (\%) & pMRI received $(n=304)$ & pMRI not received $(n=305)$ & P-value \\
\hline Age at diagnosis, years & & & $<0.001$ \\
\hline$<45$ & $67(22.0)$ & $52(17.0)$ & \\
\hline $45-54$ & $109(35.9)$ & 75 (24.6) & \\
\hline $55-64$ & $92(30.3)$ & $109(35.7)$ & \\
\hline$\geq 65$ & $36(11.8)$ & $69(22.6)$ & \\
\hline Race & & & $<0.001$ \\
\hline White & $190(62.5)$ & $130(42.6)$ & \\
\hline African-American & $114(37.5)$ & $175(57.4)$ & \\
\hline Education & & & $<0.001$ \\
\hline Below college & $124(40.8)$ & $182(59.7)$ & \\
\hline College graduate & $139(45.7)$ & $91(29.8)$ & \\
\hline Unknown & $41(13.5)$ & $32(10.5)$ & \\
\hline Health insurance & & & $<0.001$ \\
\hline Non-private ${ }^{*}$ & $49(16.1)$ & $105(34.4)$ & \\
\hline Private & $236(77.6)$ & $185(60.7)$ & \\
\hline Unknown & $19(6.3)$ & $15(4.9)$ & \\
\hline Body mass index, $\mathrm{kg} / \mathrm{m}^{2}$ & & & 0.009 \\
\hline ㄴ4.9 & $117(38.5)$ & $84(27.5)$ & \\
\hline $25.0-29.9$ & $87(28.6)$ & $83(27.2)$ & \\
\hline 230.0 & 97 (31.9) & $134(43.9)$ & \\
\hline Unknown & $3(1.0)$ & $4(1.3)$ & \\
\hline Family history of breast cancer & & & 0.195 \\
\hline First degree relative & $78(25.7)$ & $63(20.7)$ & \\
\hline Second degree relative & $58(19.1)$ & $52(17.0)$ & \\
\hline None & $168(55.3)$ & $190(62.3)$ & \\
\hline Clinical presentation & & & 0.024 \\
\hline Patient finding & $141(46.4)$ & $114(37.4)$ & \\
\hline Physician finding or screening mammography & $163(53.6)$ & $191(62.6)$ & \\
\hline \multicolumn{4}{|l|}{ Additional investigations } \\
\hline Diagnostic mammogram & $289(95.1)$ & $292(95.7)$ & 0.692 \\
\hline Diagnostic ultrasonography & $258(84.9)$ & $228(74.8)$ & 0.002 \\
\hline Genotype testing & $72(23.7)$ & $33(10.8)$ & $<0.001$ \\
\hline Additional biopsies & $31(10.2)$ & $14(4.6)$ & $<0.001$ \\
\hline Method of diagnosis & & & $<0.001$ \\
\hline Percutaneous biopsy & $269(88.5)$ & $231(75.7)$ & \\
\hline Surgical biopsy & $35(11.5)$ & $74(24.3)$ & \\
\hline
\end{tabular}

Abbreviations: pMRI= pre-operative magnetic resonance imaging.

* Non-private insurance includes Medicare, Medicaid, no insurance, and charity care. 
$P$-values were derived from chi-square test for proportions. 
Table 2

Tumor and treatment characteristics of the study population, by receipt of pMRI

\begin{tabular}{|c|c|c|c|}
\hline Tumor characteristics, n (\%) & pMRI received $(n=304)$ & pMRI not received $(n=305)$ & $\underline{P \text {-value }}$ \\
\hline Tumor grade & & & 0.660 \\
\hline Well differentiated & $61(20.1)$ & $53(17.4)$ & \\
\hline Moderately differentiated & $119(39.1)$ & $130(42.6)$ & \\
\hline Poorly differentiated & $107(35.2)$ & $109(35.7)$ & \\
\hline Unknown & $17(5.6)$ & $13(4.3)$ & \\
\hline Tumor histology & & & 0.345 \\
\hline Invasive lobular & $35(11.5)$ & $28(9.2)$ & \\
\hline Other invasive & $269(88.5)$ & $277(90.8)$ & \\
\hline Tumor size & & & 0.326 \\
\hline$\leq 1.0 \mathrm{~cm}$ & $104(34.2)$ & $116(38.0)$ & \\
\hline$>1.0 \mathrm{~cm}$ & $200(65.8)$ & $189(62.0)$ & \\
\hline Lymph node status & & & 0.002 \\
\hline Negative & $206(67.8)$ & $238(78.0)$ & \\
\hline Positive & 97 (31.9) & $62(20.3)$ & \\
\hline Unknown & $1(0.3)$ & $5(1.6)$ & \\
\hline Multifocal or Multicentric tumor & & & 0.042 \\
\hline Yes & $72(23.7)$ & $52(17.0)$ & \\
\hline No & $232(76.3)$ & $253(83.0)$ & \\
\hline Margin status at initial surgery & & & 0.478 \\
\hline Positive & $38(12.5)$ & $41(13.4)$ & \\
\hline Close & $47(15.5)$ & $37(12.1)$ & \\
\hline Negative & $218(71.7)$ & $227(74.4)$ & \\
\hline Unknown & $1(0.3)$ & $0(0.0)$ & \\
\hline \multicolumn{4}{|l|}{ Receptor Status } \\
\hline ER positive & $239(78.6)$ & $235(77.0)$ & 0.896 \\
\hline PR positive & $214(70.4)$ & $194(63.6)$ & 0.189 \\
\hline HER2 positive & $50(16.4)$ & $53(17.4)$ & 0.954 \\
\hline Triple negative & $37(12.2)$ & $51(16.7)$ & 0.277 \\
\hline Initial surgery & & & 0.194 \\
\hline Breast conserving surgery & $188(61.8)$ & $204(66.9)$ & \\
\hline Mastectomy & $116(38.2)$ & $101(33.1)$ & \\
\hline Adjuvant therapy & & & 0.129 \\
\hline Chemotherapy only & $66(21.7)$ & $63(20.7)$ & \\
\hline Hormonal therapy only & $105(34.5)$ & $125(41.0)$ & \\
\hline Chemotherapy and hormonal therapy & $119(39.1)$ & $96(31.5)$ & \\
\hline None & $14(4.6)$ & $21(6.9)$ & \\
\hline Type of surgical facility & & & 0.651 \\
\hline Teaching-based & $171(56.3)$ & $166(54.4)$ & \\
\hline Community-based & $133(43.8)$ & $139(45.6)$ & \\
\hline
\end{tabular}


Abbreviations: pMRI= pre-operative magnetic resonance imaging; $\mathrm{ER}=$ estrogen receptor; $\mathrm{PR}=$ progesterone receptor; $\mathrm{HER} 2=$ human epidermal growth factor receptor 2 .

$P$-values were derived from chi-square test for proportions. 
Table 3

Time to surgery and Rate of Re-operation and CPM, by receipt of pMRI

\begin{tabular}{lcccc}
\hline Outcomes & pMRI received & pMRI not received & \multirow{2}{P\text{P-value}}{} \\
Time to surgery, days & $\mathrm{n}=281$ & $\mathrm{n}=291$ & \\
Geometric mean $(95 \% \mathrm{CI})$ & $35.0(32.6,37.7)$ & $25.9(24.1,27.8)$ & $<0.001$ \\
Re-operation, n (\%) & $\mathrm{n}=304$ & $\mathrm{n}=305$ & \\
Yes & $55(18.1)$ & $62(20.3)$ & 0.484 \\
No & $249(81.9)$ & $243(79.7)$ & \\
CPM, n (\%) & $\mathrm{n}=304$ & $\mathrm{n}=305$ & \\
Yes & $49(16.1)$ & $16(5.2)$ & $<0.001$ \\
No & $255(83.9)$ & $289(94.8)$ & \\
\hline
\end{tabular}

Abbreviations: pMRI= pre-operative magnetic resonance imaging; $\mathrm{CI}=$ confidence interval; $\mathrm{CPM}=$ contralateral prophylactic mastectomy.

$P$-values were derived from general linear model for means and chi-square test for proportions. 
Table 4

Time to surgery and Rate of Re-operation and CPM, by subject characteristics

\begin{tabular}{|c|c|c|c|}
\hline Characteristics & $\begin{array}{l}\text { Time to surgery, geometric mean days }(95 \% \\
\text { CI) } \\
\mathrm{n}=572\end{array}$ & $\begin{array}{l}\underline{\text { Re-operation rate, } \%} \\
\underline{\mathrm{n}=609}\end{array}$ & $\begin{array}{l}\text { CPM rate, \% } \\
\mathrm{n}=609\end{array}$ \\
\hline \multicolumn{4}{|l|}{ Age at diagnosis, years } \\
\hline$<45$ & $30.4(26.9,34.3)$ & 19.3 & 25.2 \\
\hline $45-54$ & $30.8(28.0,33.8)$ & 18.5 & 13.6 \\
\hline $55-64$ & $29.2(26.7,32.0)$ & 21.9 & 4.5 \\
\hline \multirow[t]{2}{*}{$\geq 65$} & $30.1(26.6,34.1)$ & 15.2 & 1.0 \\
\hline & $p=0.877$ & $p=0.560$ & $p<0.001$ \\
\hline \multicolumn{4}{|l|}{ Race } \\
\hline White & $28.0(26.0,30.0)$ & 17.8 & 15.9 \\
\hline \multirow[t]{2}{*}{ African-American } & $32.6(30.2,35.1)$ & 20.8 & 4.8 \\
\hline & $p=0.004$ & $p=0.356$ & $p<0.001$ \\
\hline \multicolumn{4}{|l|}{ Education } \\
\hline Below college & $29.7(27.6,32.0)$ & 19.9 & 8.5 \\
\hline$\geq$ College graduate & $29.1(26.8,31.7)$ & 20.4 & 13.9 \\
\hline \multirow[t]{2}{*}{ Unknown } & $34.7(29.9,40.3)$ & 12.3 & 9.6 \\
\hline & $p=0.125$ & $p=0.279$ & $p=0.126$ \\
\hline \multicolumn{4}{|l|}{ Health insurance } \\
\hline Non-private & $32.5(29.3,36.1)$ & 16.9 & 2.6 \\
\hline Private & $29.0(27.2,30.9)$ & 19.5 & 13.8 \\
\hline \multirow[t]{2}{*}{ Unknown } & $32.7(26.3,40.6)$ & 26.5 & 8.8 \\
\hline & $p=0.126$ & $p=0.425$ & $p<0.001$ \\
\hline \multicolumn{4}{|l|}{ Body mass index, $\mathrm{kg} / \mathrm{m}^{2}$} \\
\hline$\leq 24.9$ & $29.0(26.5,31.8)$ & 11.9 & 20.4 \\
\hline $25.0-29.9$ & $30.4(27.6,33.6)$ & 20.6 & 7.6 \\
\hline \multirow{2}{*}{$\geq 30.0$} & $30.7(28.2,33.4)$ & 25.1 & 4.8 \\
\hline & $p=0.816$ & $p=0.003$ & $p<0.001$ \\
\hline \multicolumn{4}{|l|}{ Family history } \\
\hline First degree relative & $31.1(27.9,34.6)$ & 17.0 & 13.5 \\
\hline Second degree relative & $31.2(27.6,35.2)$ & 20.0 & 17.3 \\
\hline \multirow[t]{2}{*}{ None } & $29.3(27.3,31.4)$ & 19.8 & 7.5 \\
\hline & $p=0.525$ & $p=0.753$ & $p=0.007$ \\
\hline \multicolumn{4}{|l|}{ Clinical presentation } \\
\hline Patient finding & $29.2(26.9,31.7)$ & 15.7 & 14.9 \\
\hline \multirow[t]{2}{*}{ Physician finding or screening mammography } & $30.6(28.6,32.7)$ & 21.8 & 7.6 \\
\hline & $p=0.387$ & $p=0.061$ & $p=0.004$ \\
\hline \multicolumn{4}{|l|}{ Genotype testing } \\
\hline Done & $33.3(29.4,37.8)$ & 18.1 & 35.2 \\
\hline Not done & $29.4(27.8,31.1)$ & 19.4 & 5.6 \\
\hline
\end{tabular}




\begin{tabular}{|c|c|c|c|}
\hline \multirow[b]{2}{*}{ Characteristics } & $\begin{array}{l}\text { Time to surgery, geometric mean days }(95 \% \\
\text { CI) }\end{array}$ & \multirow{2}{*}{$\begin{array}{l}\underline{\text { Re-operation rate, } \%} \\
\underline{\mathrm{n}=609}\end{array}$} & \multirow{2}{*}{$\begin{array}{l}\text { CPM rate, \% } \\
\mathrm{n}=609\end{array}$} \\
\hline & $\underline{n}=572$ & & \\
\hline & $p=0.076$ & $p=0.750$ & $p<0.001$ \\
\hline \multicolumn{4}{|l|}{ Method of diagnosis } \\
\hline Percutaneous biopsy & $30.8(29.0,32.6)$ & 21.4 & 10.8 \\
\hline \multirow[t]{2}{*}{ Surgical biopsy } & $27.1(24.0,30.6)$ & 9.2 & 10.1 \\
\hline & $p=0.064$ & $p=0.003$ & $p=0.828$ \\
\hline \multicolumn{4}{|l|}{ Tumor grade } \\
\hline Well differentiated & $31.3(27.9,35.2)$ & 20.2 & 7.9 \\
\hline Moderately differentiated & $29.4(27.1,31.9)$ & 16.9 & 11.2 \\
\hline Poorly differentiated & $30.0(27.4,32.8)$ & 20.8 & 11.6 \\
\hline \multirow[t]{2}{*}{ Unknown } & $30.9(24.5,39.0)$ & 23.3 & 10.0 \\
\hline & $p=0.835$ & $p=0.649$ & $p=0.751$ \\
\hline \multicolumn{4}{|l|}{ Tumor histology } \\
\hline Invasive lobular & $26.7(22.7,31.4)$ & 17.5 & 11.1 \\
\hline \multirow[t]{2}{*}{ Other Invasive } & $30.5(28.8,32.2)$ & 19.4 & 10.6 \\
\hline & $p=0.128$ & $p=0.709$ & $p=0.905$ \\
\hline \multicolumn{4}{|l|}{ Tumor size } \\
\hline$\leq 1.0 \mathrm{~cm}$ & $31.4(28.9,34.2)$ & 21.4 & 10.5 \\
\hline \multirow[t]{2}{*}{$>1.0 \mathrm{~cm}$} & $29.2(27.4,31.3)$ & 18.0 & 10.8 \\
\hline & $p=0.193$ & $p=0.311$ & $p=0.895$ \\
\hline \multicolumn{4}{|l|}{ Lymph node status } \\
\hline Negative & $30.2(28.4,32.0)$ & 19.1 & 9.5 \\
\hline Positive & $29.7(26.7,33.1)$ & 20.1 & 14.5 \\
\hline \multirow[t]{2}{*}{ Unknown } & $29.9(18.0,49.9)$ & 0.0 & 0.0 \\
\hline & $p=0.976$ & $p=0.469$ & $p=0.150$ \\
\hline \multicolumn{4}{|c|}{ Multifocal or Multicentric tumor } \\
\hline Yes & --- & 25.0 & 17.7 \\
\hline \multirow[t]{2}{*}{ No } & --- & 17.7 & 8.9 \\
\hline & & $p=0.067$ & $p=0.004$ \\
\hline \multicolumn{4}{|l|}{ Margin status at initial surgery } \\
\hline Positive & --- & 81.0 & --- \\
\hline Close & ---- & 40.5 & ---- \\
\hline \multirow[t]{2}{*}{ Negative } & ---- & 4.0 & --- \\
\hline & & $p<0.001$ & \\
\hline \multicolumn{4}{|l|}{ Initial surgery } \\
\hline Mastectomy & $36.5(33.4,39.9)$ & ---- & ---- \\
\hline \multirow[t]{2}{*}{ Lumpectomy } & $27.3(25.6,29.0)$ & ---- & ---- \\
\hline & $p<0.001$ & & \\
\hline \multicolumn{4}{|l|}{ Type of surgical facility } \\
\hline Teaching-based & $31.2(29.1,33.5)$ & 15.4 & 12.5 \\
\hline Community-based & $28.7(26.6,31.0)$ & 23.9 & 8.5 \\
\hline
\end{tabular}




\begin{tabular}{|c|c|c|c|}
\hline \multirow{3}{*}{ Characteristics } & $\begin{array}{l}\text { Time to surgery, geometric mean days }(95 \% \\
\text { CI) }\end{array}$ & $\underline{\text { Re-operation rate, } \%}$ & CPM rate, \% \\
\hline & $\underline{n}=572$ & $\underline{n}=609$ & $\underline{n}=609$ \\
\hline & $p=0.117$ & $p=0.008$ & $p=0.111$ \\
\hline
\end{tabular}

Abbreviations: $\mathrm{CI}=$ confidence interval; $\mathrm{CPM}=$ contralateral prophylactic mastectomy .

$P$-values were derived from general linear model for means and chi-square test for proportions. 
Table 5

Unadjusted and adjusted association between pMRI and study outcomes

\begin{tabular}{|c|c|c|c|}
\hline Outcomes & pMRI & Unadjusted geometric mean $(95 \% \mathrm{CI})$ & Adjusted geometric mean $(95 \% \mathrm{CI})^{q /}$ \\
\hline \multirow{3}{*}{ Time to surgery, days } & Yes & $35.0(32.6,37.7)$ & $38.9(34.5,41.6)$ \\
\hline & No & $25.9(24.1,27.8)$ & $27.5(25.2,30.0)$ \\
\hline & & Unadjusted RR (95\% CI) & Adjusted RR $(95 \% \mathrm{CI})$ \\
\hline \multirow{3}{*}{ Re-operation } & Yes & $0.89(0.64,1.23)$ & $0.76(0.54,1.08)^{\dagger}$ \\
\hline & No & Ref & Ref \\
\hline & Yes & $3.07(1.79,5.28)$ & $1.82(1.06,3.12)^{f}$ \\
\hline CPM & No & Ref & Ref \\
\hline
\end{tabular}

Abbreviations: $\mathrm{pMRI}=$ pre-operative magnetic resonance imaging; $\mathrm{CI}=$ confidence interval; $\mathrm{RR}=$ relative risk; $\mathrm{CPM}=$ contralateral prophylactic mastectomy.

II Adjusted for age, race, education, insurance, and type of initial surgery.

${ }^{\dagger}$ Adjusted for age, race, education, insurance, body mass index, method of diagnosis, histology, multifocality/multicentricity and surgical facility.

${ }^{\ddagger}$ Adjusted for age, race, education, insurance, body mass index, family history of breast cancer, genotype testing, clinical presentation, multifocality/multicentricity, and surgical facility. 